\title{
The Fukuyama Cross-Coupling Reaction
}

\section{Key words}

palladium catalysis

Fukuyama cross-

coupling

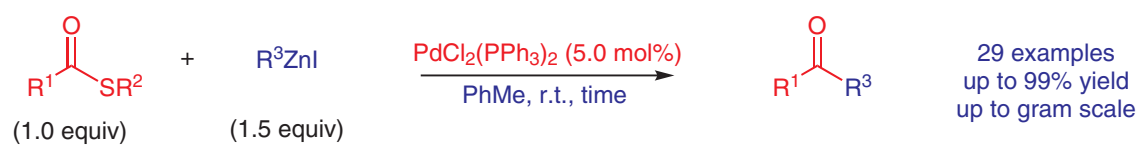

thioesters

alkylzinc

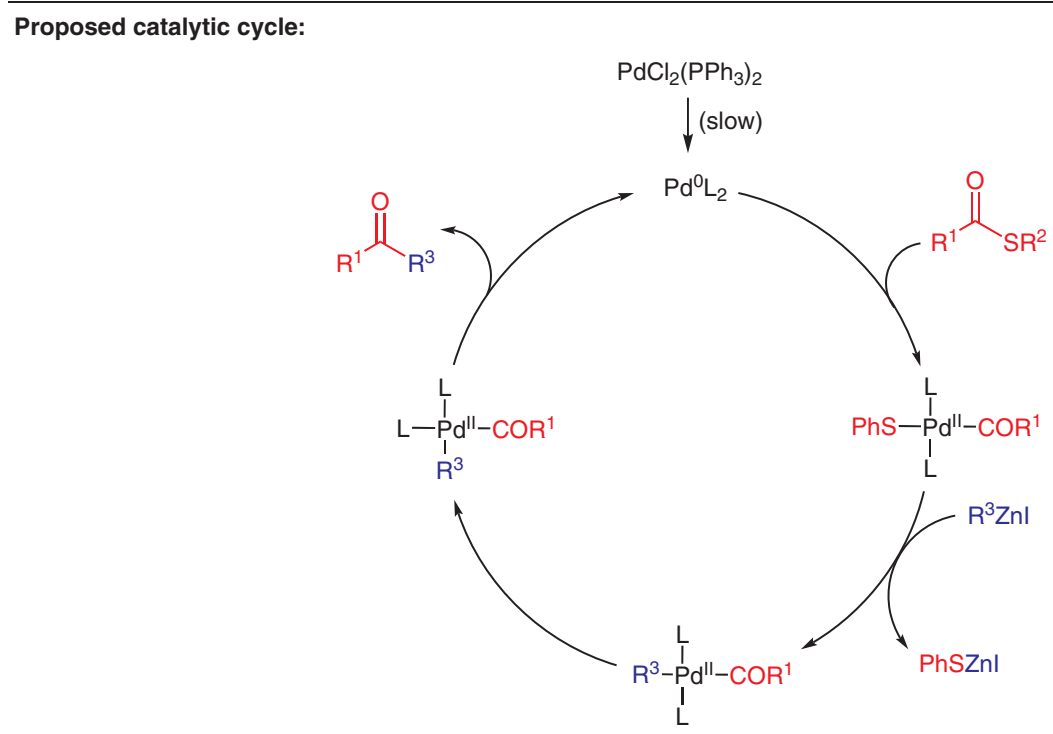

Selected examples:<smiles>CCC(=O)CCc1ccc(OC)cc1</smiles>

$91 \%$ yield<smiles>CCC(=O)CCC(=O)c1ccccc1</smiles>

$99 \%$ yield<smiles>CCOC(=O)CCCC(=O)CCc1ccc(OC)cc1</smiles>

$92 \%$ yield<smiles>CCC(=O)C(OC(C)=O)c1ccccc1</smiles>

$75 \%$ yield
Significance: Fukuyama and co-workers reported a palladium-catalyzed cross-coupling between thioesters and organozinc reagents to afford the corresponding ketone products. The reaction proceeds under mild conditions, shows good functional group tolerance, and affords access to the product in excellent yields.
Comment: The reaction tolerates the presence of sensitive functional groups within the thioester, including aldehydes, ketones, acetates, and even aryl bromides/chlorides. The selectivity supports a faster rate of oxidation into the $\mathrm{C}-\mathrm{S}$ bond, versus oxidative addition into the aryl halides, or nucleophilic addition to aldehydes.

Review: J. Lou, Q. Wang, P. Wu, H. Wang, Y.-G. Zhou, Z. Yu Chem. Soc. Rev. 2020, 49, 4307-4359. 